11.7. If universal military service is adopted, the field of secondary education will have the added responsibility of increasing the efficiency and quantity of instruction given in mathematics and physical science to the students of better than average ability.

11.8. The Armed Forces should encourage young men to continue their education during military service by taking correspondence work through regular school channels, and the Armed Forces should pay the costs of such study if a man carries it through diligently.

\title{
PREDOCTORAL FELLOWSHIPS IN THE NATURAL SCIENCES
}

The National Research Council announces that it is now ready to receive nominations and applications for the predoctoral fellowships in the natural (that is mathematical, physical, and biological) sciences which it is administering under a grant from the Rockefeller Foundation. These fellowships are intended to assist young men and women, whose graduate study has been prevented or interrupted by the war, to complete their work for the doctorate. It is hoped that these fellowships will do much to accelerate the recovery of the scientific vigor and competence of the country which is so seriously threatened by the loss of almost two graduate school generations of scientifically trained men and women.

This program will be administered by a Committee on Predoctoral Fellowships of the National Research Council whose members are Henry A. Barton, Charles W. Bray, Detlev W. Bronk, Luther P. Eisenhart, Ross G. Harrison (Chairman-National Research Council, ex officio), W. A. Noyes, Jr., and John T. Tate, chairman; Enid Hannaford, secretary.

The annual stipend will be $\$ 1200$ for single persons and $\$ 1800$ for married men. In general it is expected that each recipient will spend at least eleven months per year on academic work. An additional allowance up to $\$ 500$ per year will be made for tuition fees. Fellowships granted to individuals who are eligible for educational support from the "G.I. Bill of Rights" will be at such stipends as to bring the total income from these two sources to that which would be received at the above rates.

Each fellow, before entering on his graduate studies, will submit for review by the Committee on Predoctoral Fellowships a schedule, 
approved by the dean of his graduate school, for the completion of his work for the doctorate. This schedule, as approved by the committee, will constitute an informal agreement upon the basis of which stipend payments will be made. At the discretion of the university concerned the fellowship stipend may be supplemented by university grants. All such supplementary sources of income should be made a matter of record with the committee. The progress of the fellows will be subject to periodic review by the committee which reserves the right to cancel fellowships when in their judgment satisfactory progress is not being maintained.

Prospective candidates for these fellowships are urged to apply at once even though they may be unable to undertake their graduate study in the immediate future. Information concerning these fellowships and Nomination-Application blanks are being mailed out widely to graduate schools and wartime research laboratories. They may also be obtained by writing directly to the Secretary, Committee on Predoctoral Fellowships, National Research Council, 2101 Constitution Avenue N.W., Washington 25, D. C. 